\title{
Outcomes in Hospitalized Ischemic Stroke Patients with Dementia on Admission: A Population-Based Cohort Study
}

\author{
Charlotte Zerna, Mary P. Lindsay, Jiming Fang, Richard H. Swartz, Eric E. Smith
}

\begin{abstract}
Background: Dementia prevalence is rising, and it will double in the next 20 years. This study sought to understand the prevalence of dementia in hospitalized patients with ischemic stroke, and its impact on outcomes. Methods: Using the Canadian Institute of Health Information's (CIHI) Discharge Abstract Database (DAD), all acute ischemic stroke admissions from April 2003 to March 2015 in Canada (excluding Quebec) were analyzed. Concurrent dementia at the time of admission was assessed based on hospital diagnostic codes. Characteristics and in-hospital outcomes were compared in patients with and without dementia using $\chi^{2}$ and negative binomial, as well as Poisson regression analysis. Results: During the observed period, 313,138 people were admitted to a hospital in Canada for an ischemic stroke. Of those, $21,788(7.0 \%)$ had a concurrent diagnosis of dementia. People with dementia had older median age (84 vs. 76 years; $p<0.0001)$, were more often female (59.6\% vs. $48.4 \% ; p<0.0001)$ and more often had Charlson-Deyo Comorbidity Index $\geq 2(64.5 \%$ vs. $43.5 \% ; p<0.0001$ ). Patients with dementia were less likely to be discharged to a rehabilitation facility (adjusted risk ratio [RR] 3.089, $95 \%$ confidence interval $[\mathrm{CI}] 2.992-3.188, p<0.0001$ ) or home independently (adjusted RR 0.756, 95\% CI 0.737-0.776, $p<0.0001$ ). Interpretation: Approximately 1 in 13 hospitalized ischemic stroke patients has coded dementia. Patients with ischemic stroke and concurrent dementia have higher mortality, face significantly more dependence after stroke and utilize greater healthcare resources than stroke patients without dementia. Causative conclusions are limited by the administrative data source. Early care planning and coordination could potentially optimize outcomes.
\end{abstract}

RÉSUMÉ: Évolution de l'état de santé de patients victimes d'un AVC ischémique et atteints de démence au moment de leur admission. Contexte: On le sait, la prévalence de la démence est en hausse et devrait doubler au cours des 20 prochaines années. Cette étude a donc cherché à mesurer la prévalence de la démence chez des patients hospitalisés à la suite d'un AVC ischémique et l'impact que cela entraîne sur l'évolution de leur état de santé. Méthodes: Pour analyser toutes les admissions consécutives à un AVC ischémique aigu, et ce, d'avril 2003 à mars 2015 dans tout le pays (à l'exception du Québec), nous avons fait appel aux métadonnées de la Base de données sur les congés des patients (BDCP) de l'Institut canadien d'information sur la santé (ICIS). Les cas de démence concomitants au moment de l'admission ont été évalués en fonction de codes diagnostics propres aux hôpitaux. Les caractéristiques des patients atteints de démence de même que l'évolution de leur état de santé une fois hospitalisés ont été comparées à celles des patients n'en étant pas atteints en recourant au test $\mathrm{du}_{X} 2$, à une distribution binomiale négative ainsi qu'à une régression de Poisson. Résultats: D'avril 2003 à mars 2015, 313138 personnes ont été admises dans un hôpital du Canada à la suite d'un AVC ischémique. De ce nombre, 21788 , soit 7,0\%, présentaient un diagnostic concomitant de démence. Les patients atteints de démence affichaient un âge médian supérieur (84 contre 76 ans ; p < 0,0001), étaient plus souvent de sexe féminin $(59,6 \%$ contre 48,4\%; p <0,0001) et montraient plus souvent des scores égaux ou supérieurs à 2 à l'indice de comorbidité de Charlson-Deyo $(64,5 \%$ contre 43,5\%; p <0,0001). Ajoutons aussi que les patients atteints de démence étaient moins susceptibles d'être transférés à un centre de réadaptation (risque relatif ajusté [RR] 3,089; IC 95\%:2,992-3,188; p <0,0001) ou d'obtenir leur congé pour retourner vivre chez eux de façon autonome (risque relatif ajusté $[\mathrm{RR}] 0,756$; IC $95 \%: 0,737-0,776 ; \mathrm{p}<0,0001$ ). Interprétation: Il appert qu'environ un patient sur treize ayant été hospitalisés à la suite d'un AVC ischémique s'est vu diagnostiqué une démence en fonction de codes propres aux établissements hospitaliers. Tous ces patients donnent à voir une mortalité plus élevée, sont nettement moins autonomes à la suite de leur AVC et vont encourir une utilisation plus importante de ressources si on les compare aux patients victimes d'un AVC n'étant pas atteints de démence. Établir ici une relation causale entre la démence et l'évolution de la santé de ces patients demeure toutefois malaisé étant donné l'origine de nos données administratives. Cela dit, une planification et une coordination précoces des soins prodigués pourraient potentiellement améliorer l'évolution de leur état de santé.

Keywords: Stroke, Dementia

doi:10.1017/cjn.2018.9

Can J Neurol Sci. 2018; 45: 290-294

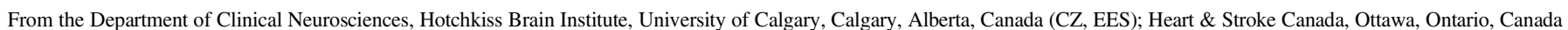

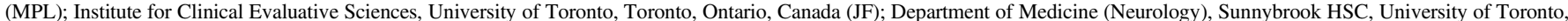
Toronto, Ontario, Canada (RHS).

Received SePtember 12, 2017. Final Revisions Submitted November 11, 2017. Date of Acceptance December 12, 2017.

Correspondence to: C. Zerna, Foothills Medical Centre, University of Calgary, 12th Floor, 140329 Street NW, Calgary, AB, Canada, T2N 2T9. Email: charlotte.zerna@ucalgary.ca
} 


\section{BACKGROUND}

Improvements in healthcare in the past century have contributed to people living longer, thus resulting in an increase of non-communicable diseases in the world's aging population. ${ }^{1}$ The number of people living with dementia worldwide was estimated by the World Health Organization at 47.5 million in 2015 and is projected to increase to 75.6 million by $2030 .^{2}$ Dementia prevalence is known to double with every 5-year increment in age after the age of 65 years. ${ }^{2}$ Two-thirds of all first ever strokes also occur in patients $>65$ years of age. ${ }^{3}$ Older stroke patients have higher risk-adjusted mortality, greater disability, longer hospital stays and are less likely to be discharged to their original place of residence when compared with their younger counterparts, ${ }^{4}$ and some of these poorer outcomes may be related to concurrent dementia. We sought to understand the prevalence of concurrent dementia in hospitalized patients with ischemic stroke (as the most common stroke subtype), as well as their characteristics and differences in their outcomes.

\section{MethodS}

We performed a population-based retrospective cohort study of all ischemic stroke patients admitted to hospital using data from the Canadian Institutes for Health Information (CIHI), a nonprofit organization that collects universally available healthcare information from 28 pan-Canadian databases. The CIHI's Discharge Abstract Database (DAD) contains demographic, administrative, and clinical data (including deaths and transfers) on all inpatient hospital discharges. Health services are administered by each of Canada's ten provinces and three territories. All hospitals in those provinces and territories (with the exception of Quebec) are required to report to the DAD; Quebec reports their data through DAD but does not allow it to be shared. ${ }^{5}$ Because all acute care hospitals in Canada provide universal access to the Canadian population, the data are nationally comprehensive. ${ }^{6}$

We analyzed a large administrative data set with anonymized record-level data from April 2003 to March 2015. Individual patient consent is not required, as broad consent is provided by patients at the time of hospitalization. These secondary analyses do not require full ethics review and have been waived by ethics reviews boards. Patients were identified using International Classification of Diseases 10 (ICD-10) codes for ischemic stroke (I63.x, I64.x), excluding transient ischemic attack (TIA) (G45.x), aneurysmal subarachnoid hemorrhage (I60.x) and intracerebral hemorrhage (I61.x). Coding of stroke in the DAD is known to have high sensitivity and specificity. ${ }^{6}$ Administrative data such as these are commonly termed secondary use research data, but when they are applied to an appropriate question with validated case definitions high-quality and reliable conclusions can be inferred. ${ }^{7}$ Stroke risk factors (hypertension, diabetes mellitus and atrial fibrillation, congestive heart failure, previous stroke/TIA) and comorbid illness were identified by ICD-10 code and by Charlson-Deyo Index (grouped 0-1 vs. $2+$ ). ${ }^{8}$ The Charlson-Deyo index is a score derived from the sum of each present comorbid illness according to the Charlson Comorbidity Score Mapping Table using either ICD-9 or ICD-10 codes. Dementia was recorded as comorbidity at the time of hospital admission, using ICD-10-CA diagnostic codes (codes used are provided in Table 1). The diagnosis of dementia thus probably reflects a chronic outpatient diagnosis; however, we cannot exclude that in some cases the stroke admission may have
Table 1: Diagnostic codes used for diagnosis of concurrent dementia at the time of hospital admission

\begin{tabular}{l|l}
\hline ICD-10 code & Diagnosis \\
\hline F00.0 or G30.0 & Dementia in Alzheimer's disease with early onset \\
\hline F00.1 or G30.1 & Dementia in Alzheimer's disease with late onset \\
\hline F00.2 or G30.8 & Dementia in Alzheimer's disease, atypical or mixed type \\
\hline F00.9 or G30.9 & Dementia in Alzheimer's disease, unspecified \\
\hline F01.0 & Vascular dementia of acute onset \\
\hline F01.1 & Multi-infarct dementia \\
\hline F01.2 & Subcortical vascular dementia \\
\hline F01.3 & Mixed cortical and subcortical vascular dementia \\
\hline F01.8 & Other vascular dementia \\
\hline F01.9 & Vascular dementia, unspecified \\
\hline R54 & Senile dementia \\
\hline
\end{tabular}

ICD $=$ International Classification of Diseases.

brought the dementia to medical attention. Discharge location categories were home without services; home with homecare services; inpatient rehabilitation; other acute care facility; complex continuing care; long-term care; died; and other. Discharge locations were used as outcome parameters.

There were no missing data. Measures of central tendency and measures of variability were calculated according to standard descriptive statistics. We used adjusted negative binomial regression models to determine the independent association of dementia with length of stay and adjusted Poisson regression models for mortality and discharge destination, controlling for the following covariates: age, sex, and pre-stroke history of cardiovascular risk factors (namely atrial fibrillation, coronary artery disease, congestive heart failure, diabetes mellitus, hypertension, previous stroke/TIA). All analyses were conducted with the use of SAS software (SAS Institute Inc, Cary, NC, USA). All reported $p$-values are two-sided.

\section{Results}

Between April 2003 and March 2015, 464,741 patients were admitted to the hospital for any stroke syndrome. Ischemic stroke was the most common diagnosis with a prevalence of $67.4 \%$, followed by TIA and subarachnoid hemorrhage both with a prevalence of $16.6 \%$ and intracerebral hemorrhage with a prevalence of $11.1 \%$. Concurrent dementia was diagnosed in $29,812(6.4 \%)$ of all of these stroke patients.

Amongst the 313,138 patients with ischemic stroke, 21,788 (7.0\%) patients had concurrent dementia. Complete baseline characteristics of ischemic stroke patients with and without concurrent dementia are displayed in Table 2. The proportion of ischemic stroke patients with dementia increased markedly with age, such that $11.1 \%$ of $>75$-year-old stroke patients had dementia.

Patients with concurrent dementia had significantly higher proportions of mortality and discharge to care facilities (Table 3). They had significantly lower proportions of discharge to rehabilitation facilities or home.

A multivariable negative binomial regression model showed that length of stay was more than $40 \%$ longer in ischemic 
Table 2: Clinical baseline characteristics of ischemic stroke patients

\begin{tabular}{l|c|c|c}
\hline & No dementia & Dementia & $p$-value \\
\hline Total & 291,350 & 21,788 & $<0.0001$ \\
\hline Female $(n[\%])$ & $140,933(48.4)$ & $12,982(59.6)$ & $<0.0001$ \\
\hline Age (years) (median $[\mathrm{IQR}])$ & $76(65-83)$ & $84(79-89)$ & \\
\hline Cardiovascular risk factors & & & $<0.0001$ \\
\hline Hypertension $(n[\%])$ & $145,572(50.0)$ & $11,615(53.3)$ & 0.0704 \\
\hline Diabetes $(n[\%])$ & $78,168(26.8)$ & $5723(26.3)$ & $<0.0001$ \\
\hline Atrial fibrillation $(n[\%])$ & $53,364(18.3)$ & $5513(25.3)$ & 0.0044 \\
\hline Previous stroke/TIA $(n[\%])$ & $31,260(10.7)$ & $2473(11.4)$ & $<0.0001$ \\
\hline Congestive heart failure $(n[\%])$ & $14,738(5.1)$ & $1822(8.4)$ & $<0.0001$ \\
\hline Charles-Deyo Index $>2(n[\%])$ & $126,809(43.5)$ & $14,064(64.5)$ & \\
\hline
\end{tabular}

$\mathrm{IQR}=$ interquartile range; $\mathrm{TIA}=$ transient ischemic attack.

stroke patients with concurrent dementia compared with those without dementia after controlling for the effects of age, sex, and pre-stroke cardiovascular risk factors (adjusted risk ratio [RR] 1.439, 95\% confidence interval [CI] 1.420-1.458, $p$-value $<0.0001)$. Multivariable Poisson regression models showed that ischemic stroke patients with dementia had a $14 \%$ higher risk of dying in hospital (adjusted RR 1.145, 95\% CI $1.112-1.179, p$-value $<0.0001)$ and three times higher risk of discharge to a long-term care facility (adjusted RR 3.089, 95\% CI 2.992-3.188, $p$-value <0.0001) compared with ischemic stroke patients without dementia. The patients with dementia were also significantly less likely to return home (adjusted RR $0.756,95 \%$ CI 0.737-0.776, $p$-value $<0.0001)$.

\section{Discussion}

The prevalence of concurrent dementia in hospitalized ischemic stroke patients in our study was low overall (7.0\%), but those patients were significantly different in regard to their baseline characteristics and outcomes compared with non-demented ischemic stroke patients. Our study shows that in-hospital mortality was increased and the ability to be discharged to home was reduced in patients coded to have dementia at the time of stroke hospitalization.

Few previous studies have examined the relationship between dementia and death after ischemic stroke, and dementia information is often missing from large stroke registries. A prior review of risk adjustment for stroke mortality failed to identify dementia as a significant factor, although this may be related to lack of ascertainment of dementia status. ${ }^{9}$ Other single-center studies examining ischemic stroke mortality found concurrent dementia to predict a four-fold increase within 6 months to 2 years during adjusted analysis. ${ }^{10,11}$ However, these studies had sample sizes well below 1000 patients and might reflect low compliance with prescribed treatment regimens in the catchment area or local approaches of treating such patients less aggressively in both the acute stage and regarding their secondary prophylaxis. A risk prediction score for post-stroke mortality rates at 1 year derived from the Registry of the Canadian Stroke Network (RCSN) in Ontario found an approximately 1.5-fold increase during adjusted analysis of data from all provincial stroke centers. $^{12}$ To our knowledge, ours is the largest population-based study to examine the association between dementia and stroke outcomes so far. We only found a $14 \%$ relative risk increase for in-hospital mortality in our study. The lower estimate compared with the other studies could be caused by a shorter follow-up period, as well as the fact that stroke mortality is also common in patients without concurrent dementia, leading to odds ratios exaggerating the relative risk.

The reason for higher mortality in ischemic stroke patients with concurrent dementia cannot be ascertained from our study, other than that it was not explained by older age or a greater

Table 3: Univariate outcome analysis of ischemic stroke patients

\begin{tabular}{l|c|c|c}
\hline & No dementia & Dementia & $p$-value \\
\hline Total number admitted & 291,350 & 21,788 & \\
\hline Total LOS $($ mean days \pm SD) & $16.11 \pm 27.41$ & $29.94 \pm 43.40$ & $<0.0001$ \\
\hline In-hospital death $(n[\%])$ & $42,463(14.6)$ & $5169(23.7)$ & $<0.0001$ \\
\hline Total number discharged & 228,887 & 16,619 & $<0.0001$ \\
\hline Long-term care facility $(n[\%])$ & $16,389(6.6)$ & $5,520(33.2)$ & $<0.0001$ \\
\hline Home $(n[\%])$ & $105,591(42.4)$ & $3211(19.3)$ & $<0.0001$ \\
\hline Rehabilitation $(n[\%])$ & $37,247(15.0)$ & $1047(6.3)$ & \\
\hline
\end{tabular}

LOS $=$ length of stay. 
number of vascular risk factors. Potential reasons could include pre-existing disabilities including gait impairment and dysphagia that can accompany dementia, more severe strokes, or a greater propensity for next of kin to pursue palliative care. Because of limitations inherent to administrative health data, we were unable to analyze pre-stroke living status, stroke severity, or palliative care orders.

Among ischemic stroke survivors, our study documented a $40 \%$ increase in risk for prolonged length of stay in the hospital. Reasons could include barriers in disposition planning owing to patient's physical functionality and orientation, as well as higher risk of complications, including risk of falls and pressure ulcers, which need prolonged medical care. ${ }^{13}$ A study of concurrent dementia among patients on an internal medicine ward admitted for acute illness revealed that the prolonged stay caused excess costs of $19 \%$ compared with other admissions. ${ }^{13}$ Therefore, early planning for discharge seems warranted in patients with dementia to try to reduce length of stay.

Hospitalized ischemic stroke patients were also significantly more often discharged to long-term care facilities and significantly less likely to return to their home. A high proportion of people with dementia need some care, ranging from support with (instrumental) activities of daily living to full personal care and round-the clock supervision. In many high-income countries, such as Canada, one-third to one-half of people with dementia live in resource- and cost-intensive residential or nursing homes. ${ }^{14}$ Dementia is imposing huge economic burdens, both through direct (medical and social care) and indirect costs (unpaid caregiving by families and friends). ${ }^{2}$ Although ischemic stroke patients with dementia were at a higher risk for discharge to longterm care, it was possible to discharge almost one in five to home. An early focus on discharge planning and home services may facilitate discharge to home rather than to a resource-intensive long-term care facility.

Strengths of the study include the large sample size and the population-based data collection, as Canada has a single-payer health system. Limitations include those common to administrative health databases: no information on pre-stroke living status, the presenting stroke severity, or the modalities of treatment provided at the receiving hospital including the use of palliative care. A prior study in the Netherlands showed high validity of diagnosis of overall dementia using ICD-9 in a nationwide register, but no such analysis has been conducted for Canada and current coding standards. ${ }^{15}$ In addition, if stroke and TIA are under-recognized or misdiagnosed in patients with dementia leading to fewer hospitalizations coded for stroke and TIA are, then the true prevalence of dementia in stroke patients could be underestimated by administrative data. It is unclear how this research undertaken in the Canadian health system might be extrapolated to other systems.

\section{Conclusion}

Approximately 1 in 13 hospitalized ischemic stroke patients have concurrent dementia as per diagnostic coding. Ischemic stroke patients with dementia have higher mortality, face significantly more dependence and utilize greater healthcare resources. Early care planning and coordination could possibly optimize the outcomes of these patients and minimize societal costs, but further research needs to be conducted in this area.

\section{ACKNOWLedgments}

Parts of this material are based on data and information provided by the Canadian Institute for Health Information. However, the analyses, conclusions, opinions and statements expressed herein are those of the author and not those of the Canadian Institute for Health Information. Funding for the data analysis was provided by the Heart and Stroke Foundation of Canada.

\section{Disclosures}

CZ, MPL, RHS and JF have nothing to disclose. EES reports other from Heart and Stroke Foundation of Canada, during the conduct of the study, as well as grants from Canadian Institutes of Health Research and grants from Brain Canada, outside the submitted work.

\section{Statement of Authorship}

$\mathrm{CZ}$ contributed to the study concept and design, interpretation of the data, as well as drafting and revising the manuscript. MPL contributed to the study concept and design, data acquisition and management, data interpretation and revising the manuscript. JF contributed to the data analysis and interpretation, as well as revising the manuscript. RHS contributed to the study concept and design, and revising the manuscript. EES contributed to the study concept and design, interpretation of the data, revising the manuscript and functioned as the senior author for this work.

\section{REFERENCES}

1. Lunenfeld B, Stratton P. The clinical consequences of an ageing world and preventive strategies. Best Pract Res Clin Obstet Gynaecol. 2013;27:643-59.

2. World Health Organization and Alzheimer's Disease International. Dementia - a public health priority. Geneva, Switzerland: WHO; 2012. p. 112.

3. Feigin VL, Forouzanfar MH, Krishnamurthi R, et al. Global and regional burden of stroke during 1990-2010: findings from the global burden of disease study 2010. Lancet. 2014;383: 245-54.

4. Benjamin EJ, Blaha MJ, Chiuve SE, et al. Heart disease and stroke statistics-2017 update: a report from the American Heart Association. Circulation. 2017;135:e146-603.

5. Canadian Institute for Health Information. DAD metadata. Available at: http://www.cihi.ca/CIHI-ext-portal/internet/en/document/types+ of+care/hospital+care/acute+care/dad_metadata (last accessed March 28, 2017).

6. Kokotailo RA, Hill MD. Coding of stroke and stroke risk factors using international classification of diseases, revisions 9 and 10. Stroke. 2005;36:1776-81.

7. Yu AY, Holodinsky JK, Zerna C, et al. Use and utility of administrative health data for stroke research and surveillance. Stroke. 2016;47:1946-52.

8. Deyo RA, Cherkin DC, Ciol MA. Adapting a clinical comorbidity index for use with ICD-9-cm administrative databases. J Clin Epidemiol. 1992;45:613-9.

9. Katzan IL, Spertus J, Bettger JP, et al. Risk adjustment of ischemic stroke outcomes for comparing hospital performance: a statement for healthcare professionals from the American Heart Association/ American Stroke Association. Stroke. 2014;45:918-44.

10. Barba R, Morin MD, Cemillan C, Delgado C, Domingo J, Del Ser T. Previous and incident dementia as risk factors for mortality in stroke patients. Stroke. 2002;33:1993-8.

11. Gao CY, Lian Y, Zhang M, et al. Association of dementia with death after ischemic stroke: a two-year prospective study. Exp Ther Med. 2016;12:1765-9. 
12. Saposnik G, Kapral MK, Liu Y, et al. Iscore: a risk score to predict death early after hospitalization for an acute ischemic stroke. Circulation. 2011;123:739-49.

13. Motzek T, Junge M, Marquardt G. [impact of dementia on length of stay and costs in acute care hospitals]. Z Gerontol Geriatr. 2017;50:59-66.
14. Macdonald A, Cooper B. Long-term care and dementia services: an impending crisis. Age Ageing. 2007;36:16-22.

15. van de Vorst IE, Vaartjes I, Sinnecker LF, Beks LJ, Bots ML, Koek HL. The validity of national hospital discharge register data on dementia: a comparative analysis using clinical data from a university medical centre. Neth J Med. 2015;73:69-75. 